\title{
SPECIAL NOTE
}

\section{Construction in Developing Countries: Need for New Concepts}

\author{
George Ofori
}

Published online: 25 January 2019

To cite this article: George Ofori (2018). Construction in developing countries: Need for new concepts. Journal of Construction in Developing Countries, 23(2): 1-6. https://doi.org/10.21315/jcdc2018.23.2.1.

To link to this article: https://doi.org/10.21315/jcdc2018.23.2.1

\begin{abstract}
Studies on the construction industries in the developing countries started in the 1960s. The aspects of the subject studied include the key components of the industries, focusing on the problems they were deemed to be facing and what should be done to develop the industries and enhance their performance. There have been arguments on whether it is appropriate to study the industries in developing countries with concepts and methods developed for industries in different contexts. This short paper contributes to this debate. It is suggested that, after nearly six decades of research, there is now an established subject of knowledge on the "construction industry in developing countries". It is argued that the context of the industry in developing countries means that more work should be done to modify the existing body of knowledge. Some possible areas where new thinking is evident are outlined.
\end{abstract}

Keywords: Construction industry, Developing country context, Construction management and economics, New concepts

\section{INTRODUCTION}

At the Association of Researchers in Construction Management (ARCOM) 2018 Conference in Belfast, Northern Ireland, on 3-5 September 2018, a panel comprising members from several countries discussed the topic: "Construction in the developing world: Where are the alternative frames of thinking?" (Chan, 2019). The discussion generated much interest among the conference participants. Some of the contributors referred to the debate on decolonising teaching curricula and research which is going on in many countries (Council on Higher Education, 2017) and argued that it is inappropriate to continue to apply concepts and ideas developed elsewhere to the developing countries, recognising the differences in the contexts. Some highlighted the need for research on all aspects of construction to seek to make practical impact in developing countries. Some others referred to the current criteria used by Editors of the leading refereed journals to decide on the quality of the papers they would accept for publication as being responsible for the tendency to use well recognised approaches. There were also some who focused on semantics and forms of wording: the meaning of "development", "developing" and "the poor" were debated.

The topic of the discussion at the ARCOM conference is important because there is a pressing need to substantially increase the capacity and capabilities of the construction industries in the developing countries where the majority of the

London South Bank University, UNITED KINGDOM

Corresponding author: oforig3@|sbu.ac.uk 
world's population live because there are significant volumes of basic infrastructure requirements to address in these countries. For example, data from the United Nations Children Emergency Fund (UNICEF) (2017a) show that by 2015, 2.3 billion people around the world lacked access to a basic sanitation service and some 850 million people did not have access to basic drinking water services (UNICEF, 2017b). Considering the big task at hand, is it appropriate to continue to try to search for possible ways of improving the capacity and capabilities of the construction industries in developing countries, using the conventional concepts and methods? Are new ways of considering the issues needed? For example, should research seek to find ways to enable the industries in these countries to progressively grow and develop as they undertake their tasks? The Editors-in-Chief of this journal have invited some senior researchers to contribute to the subject of "alternative frames of thinking on construction in developing countries". This note is one of the contributions. Some of the points in this paper can be found in Ofori (2019).

\section{BRIEF HISTORY OF STUDIES ON CONSTRUCTION IN DEVELOPING COUNTRIES}

Arguably the first attempt to undertake a study on the construction industry from the perspective of developing countries was the field work by the United Nations Expert Group on Housing (Department of Economic and Social Affairs, 1962). The group painted a picture of poor housing, sanitation and other basic infrastructure and services. It made recommendations for major efforts to improve upon the capacity and capability of the construction industries in these countries in order to address the desperate situation.

In the early 1970s, a research unit at University College London, United Kingdom considered the role of construction in the economy, undertook studies on specific construction industries and made proposals for the development of the industries in the developing countries (Turin, 1973). Coverage of aspects of the construction industries in developing countries was included in the second edition of Economic Theory and the Construction Industry (the first book on the subject of "construction industry economics") (Hillebrandt, 1985). The first full books on the subject were by the World Bank (1984) and Wells (1986).

The aspects of construction in developing countries which have been studied have included:

1. materials development: research and development on local materials, promotion of their adoption, import substitution,

2. human resource development: education and training, development of programmes deemed relevant to developing countries such as the BSC (Housing, Building and Planning) degree at the University of Science Malaysia,

3. technology development: "appropriate" and labour-based technologies, technology transfer,

4. corporate development: contractor development, joint ventures, and

5. institution building: regulations, establishment and development of professional institutions and trade associations, formation of dedicated industry development agencies. 
At the time of writing the paper, "construction in developing countries" is now an established subject: it is a teaching module in some good universities such as University College London. It has a dedicated global research group, the Working Commission 107 on Construction in Developing Countries of the International Council for Research and Innovation in Building and Construction (CIB). The Journal of Construction in Developing Countries (launched in 2005), is its main publishing outlet. The paper, "Construction in developing countries" (Ofori, 2007) which was the guest editorial note of a special issue of a top journal, Construction Management and Economics, is officially the third most read paper in the journal. The literature on the field has facilitated policy formulation in construction industry development in many countries (see Ofori, 2012a).

Despite its importance, the field of Construction in Developing Countries has largely failed to make progress in the last decade. There has not been many significant new works, or breakthroughs in knowledge. It is pertinent to examine the reasons for this lack of interest and activity might be and what can be done to revive the field. However, that is beyond the scope of this short paper.

One could argue that construction is an industry which is the same everywhere and the same principles should apply universally. Thus, there is no need for a distinct area of construction in developing countries. "Why should we contaminate pure knowledge with consideration of 'special circumstances'?". Others would claim "developing country exceptionalism" and the need to build new knowledge to suit the special circumstances of these countries (see Ofori, 2012b). CIB W107 has published a research roadmap on the subject (Rwelamila and Ogunlana, 2015), indicating that there are relevant topics to study.

\section{POSSIBLE NEW THOUGHTS}

Rather than the danger that there would be the watering down of good practice and the development of inferior techniques for the developing countries, it is evident that, after nearly six decades of studies on the construction industries in developing countries, it is pertinent to highlight some areas where it is possible, indeed necessary, to view concepts from a different perspective and contribute to knowledge. Some of these ideas are now considered and discussed.

\section{Project Support Systems}

\section{"Consider project support systems"}

The conceptualisation of the project as in the Body of Knowledge of the Project Management Institute (PMI) (2017) which comprises ten knowledge areas, should include the key knowledge area of "the business environment" which covers the particular context of the project. This includes the regulatory and administrative framework, procedures and practices in the construction industry, the infrastructure, in short, support systems for the project.

Many projects fail to meet their objectives and performance parameters, or are never completed (Williams, 2015) because of factors within the institutional framework in the country or the district where the projects in developing countries 
were undertaken. It is not appropriate to assume an operating context which is supportive of the implementation of projects. It is necessary to study the operating environment for the project in its own right.

"Only the best is good for the poor"

It is necessary to reframe project performance parameters for developing countries, and provide guidance on how to establish appropriate orders of priority in context. New parameters which should be considered include: affordability; durability; and employment generation. "Affordable housing" is a topical issue in countries at all levels of development but it is of greater relevance in the developing nations where the shortage of housing is greatest. It is estimated that one-third of urban dwellers, some 1.6 billion people, might not have decent housing by 2015; they would occupy crowded, inadequate, and unsafe housing or will be financially stretched (Woetzel et al., 2014).

It can be stated that only the best building or item of infrastructure is good for the poor because there is a lack of resources for continual maintenance and periodic repair or rebuilding, of the built item. Often, the necessary expertise is also not available. In undertaking the assessment of projects at the pre-design stage, it is necessary to consider the long-term performance of the item to be built item and of its key components.

Involving the community in the planning and development of the item would help; there is also the need for the selection of theproject, location, materials and components, and technology to be based on more complex modelling of the project parameters, taking into consideration the socio-economic context and potential impact.

\section{Social Responsibility in Construction}

"The welfare of the poor should be safeguarded by the construction industry"

The construction industry in most countries does not have a good social image (Morrell, 2015). Many initiatives have been instituted in different countries to address this. The attention has so far, been on the industry's workers. It is critical to broaden this consideration. It is necessary to establish the concept of Social Safeguarding and Benefit in construction and develop knowledge on it at project and corporate levels, given the possible impact of projects on the people who live in their environs (especially the vulnerable rural population).

The World Bank and other major lending institutions have social safeguarding norms and policies for the projects for which they provide funding (World Bank, 2017). It is necessary for researchers to build on these norms, targets and policies to devise the concept of social safeguarding and benefit in construction.

"We should learn to apply culture more effectively on our projects and in their related aspects"

It is necessary to apply culture more fully in design and project management, in this particular context, the social structure and governance systems. It would be appropriate to optimise community involvement with appropriate project 
structures and strategies. This would involve giving this aspect greater weight under stakeholder management on projects than it currently often has. The reviews of individual projects and national development plans often show that failure to involve the community in an effective manner is one of the major causes of poor project outcomes (see, for example, National Development Authority, 2015). The traditional governance systems and structures can be used to great advantage in these regards. However, this will again require project management systems which take these traditional government systems into consideration.

"Project governance should be the key in developing countries"

Owing to the difficulties in enforcing laws and regulations in developing-country contexts, for reasons including the obsolescence and lack of appropriateness of the regulations themselves, weakness of the institutional framework in many countries and lack of executive capacity, governance on projects should be given even greater attention. The construction industry's unenviable social image is partly due to the level of corruption which is evident in it in all countries (PricewaterhouseCoopers [PwC], 2014). Construction has the dubious reputation of ranking consistently last (among 19 business sectors) on the Bribe Payers Index of Transparency International (Hardoon and Heinrich, 2011).

Under circumstances where it is difficult to enforce regulations, the technical competence and experience of the project participants becomes paramount. The leadership, professionalism and ethical behaviour of construction practitioners should be accorded greater prominence. Clients and project beneficiaries have greater reliance on the professional in such an environment. This is another area where research should seek to explore the subject from the developing country perspective.

\section{CONCLUSION}

If progress is to be made in the effort to enhance the capacity and capability of the construction industries in developing countries, and thereby, improve their performance, it is necessary to consider construction from the perspective of the developing countries. This has the potential to enrich knowledge in mainstream construction management and economics. Construction in developing countries requires a richer, more complex knowledge base. Developing the building blocks of this knowledge base is a worthwhile endeavour.

\section{REFERENCES}

Chan, P. (2019). Construction in the developing world: Where are the alternative frames of thinking? ARCOM Newsletter, 36(1): 5.

Council on Higher Education (2017). Decolonising the curriculum: Stimulating the debate. Briefly Speaking, No. 3, November.

Department of Economic and Social Affairs (1962). Report of the Ad Hoc Group of Experts on Housing and Urban Development. New York: United Nations.

Hardoon, D. and Heinrich, F. (2011). Bribe Payers Index 2011 . Berlin: Transparency International. 
Hillebrandt, P.M. (1985). Economic Theory and the Construction Industry. London: Macmillan. https://doi.org/10.1007/978-1-349-17934-3.

Morrell, P. (2015). Collaboration for Change. London: The Edge.

National Development Authority (2015). Second National Development Plan 2015/16-2019/20: Uganda Vision 2010. Kampala, Uganda: National Development Authority.

Ofori, G. (2019). Reflection by Professor George Ofori, London South Bank University. ARCOM Newsletter, 36(1): 6.

(2012a). New Perspectives in Construction in Developing Countries. Abingdon: Spon Press. https://doi.org/10.4324/9780203847343.

. (2012b). Reflections on the great divide: Strategic review of the book. In G. Ofori (ed.), Contemporary Issues in Construction in Developing Countries. Abingdon: Spon Press, 1-19. https://doi.org/10.4324/9780203847350.

. (2007). Construction in developing countries. Construction Management and Economics, 25(1): 1-6. https://doi.org/10.1080/01446190601114134.

Project Management Institute (PMI) (2017). A Guide to the Project Management Body of Knowledge (PMBOK Guide). 6th Ed. Newtown Square, PA: PMI.

PricewaterhouseCoopers (PWC) (2014). Fighting Corruption and Bribery in the Construction Industry. London: PwC.

Rwelamila, P.D. and Ogunlana, S. (2015). W107: Construction in Developing Countries Research Roadmap; Report for Consultation. Rotterdam, Netherlands: International Council on Research and Innovation in Building and Construction (CIB).

Turin, D.A. (1973). Construction and Development. London: Building Economics Research Unit, University College Research Group, University College London.

United Nations Children Emergency Fund (UNICEF) (2017a). Sanitation: Current status and progress. Available at: https://data.unicef.org/topic/water-andsanitation/sanitation/.

. (2017b). Drinking water: Current status and progress. Available at: https:// data.unicef.org/topic/water-and-sanitation/drinking-water/.

Wells, J. (1986). The Construction Industry in Developing Countries: Alternative strategies for development. London: Croom Helm.

Williams, M.J. (2015). Bricks-and-mortar institutions matter: Project delivery and unfinished infrastructure in Ghana's local governments. International Growth Center Policy Brief 89105, November. London: International Growth Centre.

Woetzel, J., Ram, S., Mischke, J., Garemo, N. and Sankhe, S. (2014). A Blueprint for Addressing the Global Affordable Housing Challenge. New York: McKinsey Global Institute.

World Bank (2017). The World Bank Environmental and Social Framework. Washington DC: World Bank.

(1984). The Construction Industry: Issues and Strategies in Developing Countries. Washington DC: World Bank. 